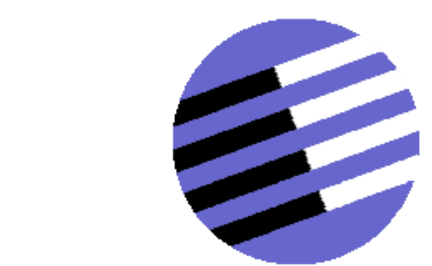

GOVERNANCE AND THE EFFICIENCY

OF ECONOMIC SYSTEMS

GESY

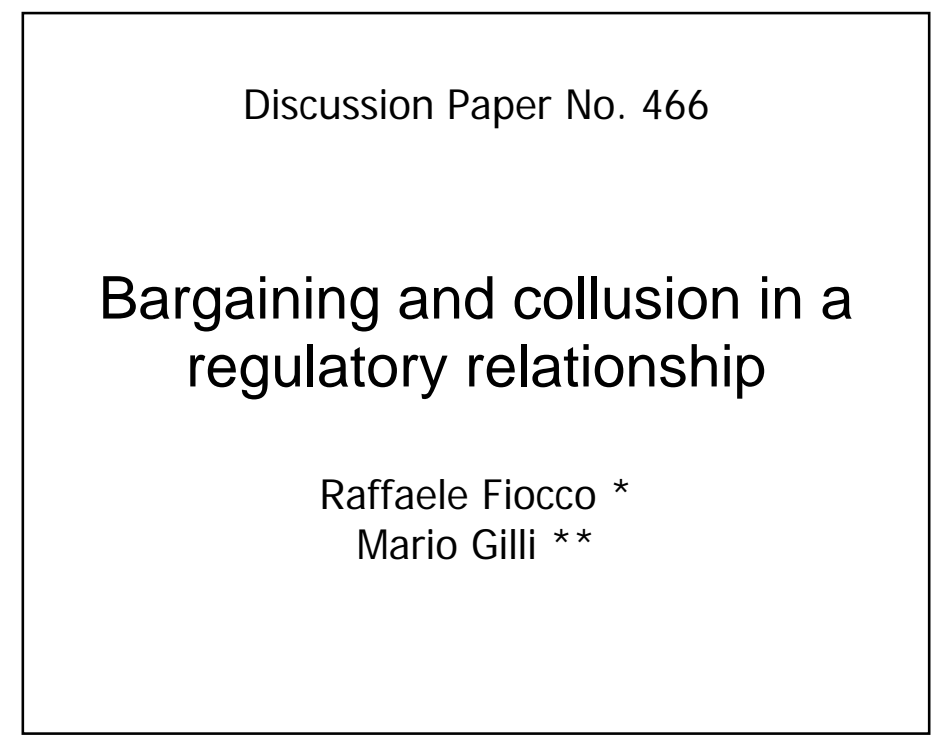

* University of Mannheim

** Bicocca University of Milan

Financial support from the Deutsche Forschungsgemeinschaft through SFB/TR 15 is gratefully acknowledged. 


\title{
Bargaining and collusion in a regulatory relationship
}

\author{
Raffaele Fiocco* and Mario Gilli ${ }^{\dagger}$
}

\begin{abstract}
We investigate regulation as the outcome of a bargaining process between a regulator and a regulated firm. The regulator is required to monitor the firm's costs and reveal its information to a political principal (Congress). In this setting, we explore the scope for collusion between the regulator and the firm, which results in the manipulation of the regulator's report on the firm's costs to Congress. The firm's benefit of collusion arises from the higher price the efficient firm is allowed to charge when the regulator reports that it is inefficient. However, a higher price reduces the gains from trade the parties can share in the bargaining process. As a result of this trade-off, the efficient firm has a stake in collusion only if the regulator's bargaining power in the regulatory relationship is relatively high. Then, we derive the optimal institutional response to collusion and characterize the conditions under which allowing collusion is desirable.
\end{abstract}

Keywords: asymmetric information, auditing, bargaining, collusion, regulation.

JEL classification: D73, D82, L51.

*Department of Economics, University of Mannheim. Email address: raffaele.fiocco@uni-mannheim.de. Tel.: +4906211811873 .

${ }^{\dagger}$ Department of Economics, Bicocca University of Milan. Email address: mario.gilli@unimib.it. Tel.: +390264483089 . 


\section{Introduction}

Regulatory intervention is usually thought of as the use of the government power to coerce for the purpose of restricting firms' decisions when unfettered competition turns out to be inappropriate. This is the case in relevant portions of electricity, gas, sanitation, telecommunications, transportation and water industries. In the economic literature, regulation is typically modeled as the power to 'command and control', and a regulatory policy is the outcome of a 'take-it-or-leave-it' offer from a regulatory agency to a regulated firm.

In practice, however, regulation is usually a process of give-and-take rather than of takeit-or-leave-it. On the one hand, regulators issue rules in the form of administrative acts which fill in details the authorizing legislation. Given the general and vague policy aims provided by the legislation (which constitutes a form of contract incompleteness), regulators are left with some power when regulating the industry. On the other hand, regulated firms generally do not comply in a fully passive manner with regulatory decisions. They may threaten to appeal against the regulator's decisions in order to obtain some revisions. The desire to avoid a rule being repealed in the courts can determine the form of the rule that is finally adopted. More importantly, this is not the only means to directly affect the regulatory outcome. A regulator usually must fulfill a set of procedural requirements that limit the exercise of policies in the form of command and control.

The US Administrative Procedure Act (APA) of 1946 provides that rulemaking procedures may be either formal, with hearings resembling a court trial, or informal, with notice of rulemaking and public comments. Concerned parties are allowed to express their viewpoints by presenting evidence on the effects of the regulator's actions and on questions of fact. Regulatory hearings are typically characterized by repeated revisions of rate proposals. In reaction to complaints, the regulator puts forward a new set of rules and amendments to the existing ones. Therefore, rulemaking is not usually the direct product of the regulator's fiat, but it arises from a process of intensive scrutiny.

This suggests that regulation tends to be the outcome of a bargaining process. Empirical evidence seems to support this view. For instance, the presence of turnover costs can weaken the threat to replace an incumbent firm which is reluctant to accept a regulatory policy. Kahn (1988) observes that in public utilities the relationship between a regulator and a regulated firm generally constitutes a bilateral monopoly which induces the parties to achieve a compromise. In their analysis of the features of the regulatory process in the US, Viscusi et al. (2005) emphasize 
the influence of private players (mainly, firms) on regulatory outcomes. Rossi (2011) explores the increasing scope for bargaining in regulatory relationships after the liberalization process. ${ }^{1}$ In a seminal survey on optimal regulation, Armstrong and Sappington (2007, p. 1564) recognize that the standard approach in the literature, which ignores negotiations between the regulator and the firm, $\langle<$ generally is adopted for technical convenience rather than for realism $\gg$.

In this paper, we model the interaction between a regulator and a regulated firm as a bargaining process. The economic literature typically assumes that the regulator has the full power to dictate the regulatory contract to the firm. The main contribution of this paper is to investigate the impact of the bargaining powers of the regulator and the firm in a regulatory process on the scope for collusion between the parties. This approach generalizes the standard command and control formulation, where all the bargaining power is allocated to the regulator, and allows a broader analysis of the optimal institutional response to collusion.

In our model, the regulator is required to monitor the firm's costs and reveal its information to a political principal (Congress). As it is well established in the literature (e.g., Tirole 1986, 1992), this raises the possibility of collusion between the firm and the regulator, which can manipulate its audit report to Congress in exchange for a side transfer from the firm. Frequent news reports of corruption and lax regulation suggest that collusion is a widespread phenomenon. Laffont and Tirole (1993, Ch. 11) report that a regulated firm has several means to influence public decision making. For instance, it can bribe the regulatory officials through gratuities or the offer of job positions in the regulated firm after their retirement ('revolving door' phenomenon). Furthermore, personal relationships provide incentives for the regulatory staff to treat their industry partners kindly. The firm may also cater to the regulator's concern for tranquility by refraining from criticizing publicly its management. As Estache and Wren-Lewis (2009) point out, the problems of collusion and corruption are particularly severe in developing countries.

It is well known in the collusion literature that an efficient firm has a stake in collusion with the regulator. We show that this standard conclusion holds only if the regulator's bargaining power is relatively high. The rationale behind our result lies in the trade-off the firm faces when colluding with the regulator. The benefit of collusion arises from the higher price the efficient firm is allowed to charge when the collusive regulator manipulates information before Congress and reports that the firm is inefficient. However, a higher price shrinks the gains from trade

\footnotetext{
${ }^{1}$ For the relevance of regulatory bargaining in the US, we also refer to the analysis of Morriss et al. (2005).
} 
the parties can share in the bargaining process. Since these gains are redistributed according to the parties' bargaining powers, a strong regulator reduces the gains the firm can appropriate. As a consequence, if the regulator's bargaining power is sufficiently high, the firm's benefit of a higher collusive price outweighs the cost of lower gains from trade, and the firm has an incentive to collude.

These results suggest that the scope for collusion crucially depends on the bargaining powers of the parties involved in the regulatory process. The bargaining power of a party can arise either from the authorizing legislation or the regulatory environment, which determines each party's strength in the regulatory relationship. If the regulator can impose to a large extent its decisions, it enjoys a high bargaining power vis-à-vis the regulated firm. In line with the standard command and control approach, our analysis predicts that the efficient firm has a stake in collusion. However, we show that a sufficiently high bargaining power of the firm removes its incentive to collude.

Afterwards, we derive the optimal institutional response to collusion. In particular, we characterize the conditions under which it is desirable to preclude collusion either through an incentive payment to the regulator or the shutdown of the inefficient firm and the conditions that make allowing collusion optimal. This can be the case when the regulator's bargaining power is high enough. The reason for this result is that a strong regulator increases the firm's stake in collusion, which makes it more costly to deter collusion. We find that allowing collusion can be also optimal when consumer demand is relatively inelastic, such as in markets for essential services (e.g., energy, sanitation). A rigid demand facilitates collusion since it reduces the loss in the gains from trade due to a higher price, and therefore deterring collusion becomes more expensive.

We feel that our analysis provides some predictions that may contribute to the practical and theoretical debate on regulation and collusion.

\section{Related literature}

As Armstrong and Sappington (2007) point out, the economic literature generally assumes that the regulator possesses all the bargaining power in its interaction with the regulated firm. A relevant exception is Spulber $(1988,1989)$, who provides a broad description of the bargaining approach to regulation and derives efficient mechanisms when regulation follows from negotiations between the firm and consumers, while the regulator is a neutral arbiter. Our approach 
is more closely related to Scarpa (1994), who considers a setting where the regulator actively participates in the regulatory process by bargaining with the firm over a regulatory policy. He shows that the firm might overinvest in order to affect the regulator's threat point. Along these lines, Amacher and Malik (1996) present a model of environmental regulation where the firm and the regulator engage in negotiations over the firm's emission standard.

These contributions ignore the possibility of collusion. Our purpose is to investigate the scope for collusion when regulation is the outcome of a bargaining process. The interest of economic literature for collusive phenomena has been sparked by the seminal contribution of Stigler (1971), which emphasizes the industry's ability to influence regulatory powers in order to obtain favors. After Stigler (1971), a wide literature has developed, which is exhaustively surveyed by Aidt (2003). The early theoretical work on collusion within the framework of asymmetric information traces back to Tirole $(1986,1992)$, which explores the effects of coalitions on the optimal incentive schemes. We refer to Laffont (2000) for a broad survey. Along these lines, Laffont and Tirole (1991) investigate the institutional responses to the possibility of collusion. Extending the previous work, Kofman and Lawarrée $(1993,1996)$ analyze the scope for collusion in the presence of honest and dishonest auditors. Khalil and Lawarrée (2006) consider the possibility of collusion when the principal cannot commit to an audit activity. A relevant contribution for our purposes is Ida and Anbashi (2008), who derive the optimal regulatory design in an adverse selection model and show that collusion can lead to information-sharing effects which are socially desirable. Interestingly, we also find that allowing collusion may be welfare-enhancing; however, our results are driven by different forces that arise from the bargaining process in a regulatory relationship.

The rest of the paper is organized as follows. Section 3 sets out the formal model. Section 4 derives the conditions under which the firm has an incentive to collude with the regulator. Section 5 characterizes the optimal institutional response to collusion. Section 6 concludes. All proofs are collected in the Appendix.

\section{The model}

Preferences Consumer demand is described by a decreasing function $q(p)$, with $\frac{\partial q}{\partial p}<0$. Consumer surplus is given by

$$
C S=\int_{p} q\left(p^{o}\right) d p^{o}-t-s_{r}
$$


where $p$ is a unit price for the good and $t$ is a fixed charge (transfer), while $s_{r} \geq 0$ denotes the remuneration to the regulator (see below). ${ }^{2}$ Limited liability constraints imply that the regulator must receive an income at least equal to its reservation wage, which is normalized to zero (e.g., Armstrong and Sappington 2007; Laffont 2000, Ch. 2).

The regulated firm's profit is

$$
\pi=p q(p)-c_{i} q(p)+t
$$

where the marginal cost $c_{i}, i \in\{l, h\}$, is the firm's private information. With probability $\nu \in(0,1)$, the cost is $c_{l}$ and with probability $1-\nu$ the cost is $c_{h}$, where $\Delta c \equiv c_{h}-c_{l}>0$. Without loss of generality, we ignore the fixed costs of production.

Regulation The political principal, labeled as Congress, cares about consumer surplus in $(1),{ }^{3}$ and delegates the task of regulation to a regulator. ${ }^{4}$ The regulator supervises the firm and obtains a signal about the firm's marginal $\operatorname{costs} c_{i}$ (see below). The regulator is also involved in a bargaining process with the firm about a regulatory policy $(p, t)$.

The regulator can be either benevolent or non-benevolent. With probability $\gamma \in(0,1)$, the regulator is benevolent and perfectly internalizes Congress' objective, i.e., $V_{b}=C S$. It always reports truthfully to Congress the signal about the firm's costs. With probability $1-\gamma$, the regulator is non-benevolent and cares only about its private income $s$, i.e., $V_{n b}=s$. This income may arise from two sources. The firm may bribe the regulator to manipulate the signal detrimental to the firm. Alternatively, in response to the threat of collusion, Congress may design an incentive payment to the regulator. This approach reflects the common idea that auditors can be of different types and, under identical circumstances, an auditor may accept a bribe while another may reject it (e.g., Kofman and Lawarrée 1996). Alternatively, some auditors may be endowed with transaction technologies which can facilitate collusion (Tirole 1992).

\footnotetext{
${ }^{2}$ The fixed payment $t$ for the good and the remuneration to the regulator $s_{r}$ can be financed through public funds (e.g., Baron 1989).

${ }^{3}$ This is in line, among others, with Laffont and Tirole (1990), who assume that regulatory institutions result from a constitution drafted by some benevolent 'founding fathers'. Our qualitative results carry over with a weight (lower than 1) on the firm's profits. Without loss of generality, we neglect the shadow cost of public funds (e.g., Laffont and Tirole 1986) due to distortionary taxation that finances transfers to the firm and the regulator. This cost increases unnecessarily further the weight of taxation in the welfare standard, without affecting the qualitative results (Armstrong and Sappington 2007).

${ }^{4}$ Delegation results from Congress' lack of time, skills or resources to perform this task (e.g., Laffont 2000, Ch. 2).
} 
Auditing The supervisory technology is characterized by perfect monitoring, so that the signal the regulator receives about the firm's costs is fully informative. Admittedly, this is a simplifying assumption. An obvious implication of introducing a supervision technology which informs the regulator only with positive probability is that the scope for collusion would be smaller. ${ }^{5}$ Note that, in our setting, we could obtain a similar effect with a higher probability of a benevolent regulator. Therefore, our qualitative results would carry over with this alternative informational structure, but the analysis would be less transparent.

The information provided by the signal cannot be verified by Congress. The assumption that an auditor may possess 'soft' (i.e., unverifiable) information about the firm's technology is well established in the literature (e.g., Baliga 1999; Faure-Grimaud et al. 2003; Laffont and Rochet 1997). In our setting, this implies that the regulator may alter the outcome of its audit activity and convey a report $r \in\left\{c_{l}, c_{h}\right\}$ which differs from the firm's real costs $c_{i}$. Forging the signal represents the regulator's degree of discretion: it may alter the report on the firm's costs since Congress cannot ascertain this manipulation. A dishonest regulator has an incentive to manipulate the signal and collude with the firm. ${ }^{6}$

The collusive agreement between the regulator and the firm is supposed to be enforceable, even though it is illegal. ${ }^{7}$ However, collusion entails a deadweight loss associated with side transfers between the firm and the regulator. For instance, a monetary bribe exposes the parties to the possibility of legal sanctions. Alternatively, the regulatory commissioners value non-monetary side transfers (e.g., entertainment or employment opportunities after the tenure in the regulatory agency) less than the monetary expenses incurred by the firm. Following Laffont and Tirole (1991, 1993, Ch. 11), we capture the inefficiency of side contracting by a shadow cost of side transfers $\mu \geq 0$. This reflects the idea that each unit of income received by the regulator costs $1+\mu$ units to the regulated firm.

Timing The sequence of events unfolds as follows.

(I) Nature chooses the type of the firm $\left(\operatorname{costs} c_{l}\right.$ or $\left.c_{h}\right)$ and the type of the regulator (benevolent

\footnotetext{
${ }^{5}$ Economic literature usually assumes that the firm observes the signal received by the regulator (e.g., Kofman and Lawarrée 1996; Laffont and Tirole 1991). When the signal is uninformative, the firm clearly does not have any incentive to collude.

${ }^{6}$ In line with the main literature (e.g., Kofman and Lawarrée 1996; Laffont and Tirole 1991), we assume that the regulator cannot forge the signal against the firm's will. For instance, the firm is able to prove before Congress its actual costs.

${ }^{7}$ The enforcement of side contracts may rely on non-judicial mechanisms, such as reputation in long-term relationships or the 'word of honor' in the one-shot relationships. We refer to Laffont and Tirole (1993, Ch. 11) for a discussion of this assumption.
} 
or non-benevolent). The firm and the regulator privately learn their type.

(II) Congress offers the regulator a contract which specifies a remuneration $s_{r}$.

(III) The regulator can either accept or reject the offer. If it rejects the offer, it receives a reservation utility (normalized to zero) and the game ends. If it accepts, it performs the audit activity and learns the firm's costs. The firm discovers whether the regulator is benevolent or non-benevolent. ${ }^{8}$

(IV) The regulator and the firm negotiate over a regulatory policy $(p, t)$. If the regulator is honest, it reports truthfully to Congress the information about the firm's costs. If the regulator is dishonest, it may collude and sign a side contract with the firm. In this case, the regulator manipulates its information and sends a report which misrepresents the firm's costs. The regulator receives from the firm a side transfer $s_{f}$ for this manipulation.

(V) Contracts are executed and the regulatory policy is implemented.

The timing of this game is fairly standard in collusion models relevant for our purposes (e.g., Kofman and Lawarrée 1996). Figure 1 illustrates the main features of the regulatory process in our setting. The equilibrium concept we adopt is the subgame perfect Nash equilibrium. We solve this game by backward induction.

Nash bargaining solution Since regulation is the outcome of a bargaining process, we need to find a model for this approach. It is well known that the outcome of a bargaining game is very sensitive to all the details of the negotiation process as well as to the delay costs of the players, namely, to all the bargaining protocols. For instance, in a simple one-shot simultaneous offer protocol, there exist multiple subgame perfect equilibria even using strong refinement concepts (Sákovics 1993). Hence, rather than describe the bargaining procedure in full detail, we prefer to characterize the bargaining outcome by adopting the cooperative Nash $(1950,1953)$ bargaining solution.

As Spulber (1989, Ch. 2) emphasizes, a crucial feature of a regulatory hearing process is the direct interaction between players which may result in a consensus, so that the regulatory bargaining game can be modeled as a cooperative game. Even though there are alternative cooperative concepts, we feel that the Nash bargaining solution is the most convincing and effective for our purposes. This modeling choice can be justified on several grounds. First, the

\footnotetext{
${ }^{8}$ This assumption is quite common in the collusion literature (e.g., Kofman and Lawarrée 1996). The firm can discover the regulator's type by proposing to collude. A benevolent regulator does not accept the proposal, while a non-benevolent regulator is willing to collude. Attempted bribery is not punishable, since it is extremely difficult or costly to prove. Alternatively, the regulator can show its type by taking the initiative to collude.
} 


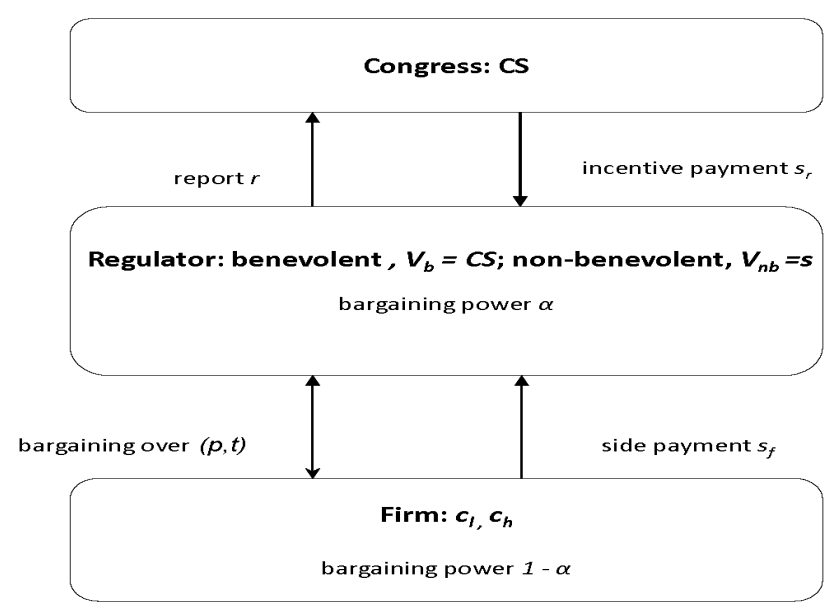

Figure 1: The three-tier regulatory process

generality of the Nash solution avoids the specification of a particular extensive form structure. ${ }^{9}$ Second, the Nash solution is efficient so that our results do not depend on the unexploited gains from trade in the specific bargaining procedures which may be considered. This implies that our approach might underestimate the transaction costs between the colluding parties; however, we capture this aspect with a shadow cost of side transfers. Third, the uniqueness of the Nash solution allows Congress to anticipate the bargaining outcome, which is helpful for the derivation of Congress' optimal response. Fourth, the asymmetric version of the Nash solution captures in a simple but effective manner the parties' bargaining powers, which play a crucial role in our analysis. As we will show, the Nash solution leads to tractable calculations and plausible results of some interest.

\section{The firm's incentive to collude}

We first characterize the regulatory policy when the regulator is benevolent. In this case, it cares about consumer surplus, i.e., $V_{b}=C S$, and collusion is not an issue. Hence, Congress finds it optimal to provide the regulator with the lowest income, i.e., $s_{r}=0$. Afterwards, we examine the firm's incentive to collude when the regulator is non-benevolent.

Using the Nash bargaining approach, when the firm's cost is $c_{i}, i \in\{l, h\}$, the outcome of

\footnotetext{
${ }^{9}$ It is well known that the Nash solution can arise in different extensive form structures (e.g., Binmore and Dasgupta 1987; Osborne and Rubinstein 1990).
} 
bargaining over a regulatory policy $(p, t)$ is the solution to the following maximization problem

$$
\max _{p, t}[C S(p, t)]^{\alpha} \times\left[\pi\left(p, t ; c_{i}\right)\right]^{1-\alpha} \quad \text { s.t. } \quad C S(p, t) \geq 0, \quad \pi\left(p, t ; c_{i}\right) \geq 0
$$

where $\alpha \in[0,1]$ denotes the regulator's bargaining power and $1-\alpha$ the firm's bargaining power in the negotiation process. A high $\alpha$ means that the regulator is powerful vis-à-vis the firm. This may follow from the authorizing legislation or statutory rules, which give the regulator a large influence on the regulatory outcome. In particular, if $\alpha=1$, the regulator has full bargaining power and can make a take-it-or-leave-it offer to the firm. Conversely, if $\alpha$ is low, the firm has the power to crucially affect the regulatory policy, for instance by threatening to appeal against the regulatory proposals. Since the regulatory relationship constitutes a bilateral monopoly (Kahn 1988), it is natural to assume that production does not occur if bargaining fails. Hence, the utility associated with the disagreement outcome is normalized to zero for both players.

The following lemma summarizes the main features of the regulatory policy.

Lemma 1 If the regulator is benevolent, the regulatory policy exhibits the following features:

(i) the price equals marginal costs, i.e., $p^{b}=c_{i}$

(ii) the fixed charge amounts to $t^{b}=(1-\alpha) \int_{c_{i}} q(p) d p$

(iii) the parties' payoffs are

$$
\begin{aligned}
& C S^{b}=\alpha \int_{c_{i}} q(p) d p \\
& \pi^{b}=(1-\alpha) \int_{c_{i}} q(p) d p .
\end{aligned}
$$

Since the Nash bargaining solution is efficient, the negotiated regulatory policy implements marginal cost pricing, independently of the parties' bargaining powers. A price equal to marginal costs maximizes the gains from trade the parties can share, which amount to $\int_{c_{i}} q(p) d p$. The fixed charge $t$ redistributes these gains between parties according to their bargaining powers.

Now, we turn to the possibility of collusion between the regulator and the firm. A dishonest regulator, which cares only about its income, may manipulate the outcome of the audit activity in exchange for a side transfer from the firm and send Congress a report $r \in\left\{c_{l}, c_{h}\right\}$ that differs from the firm's real costs $c_{i}$. As we are interested in the scope for collusion, we assume for the time being that Congress does not prevent collusion, which implies that the regulator still receives the lowest income, i.e., $s_{r}=0$. Since from Lemma 1 Congress can an- 
ticipate the regulatory outcome in the light of the report $r$, the regulatory outcome between a collusive regulator and the firm, which prevents collusion detection, is such that $p^{c}=r$ and $t^{c}=(1-\alpha) \int_{r} q(p) d p \cdot{ }^{10}$

To investigate the scope for collusion, we denote by $\Delta \pi\left(\alpha, c_{i} ; c_{j}\right) \equiv \pi\left(\alpha, c_{i} ; c_{j}\right)-\pi\left(\alpha, c_{i} ; c_{i}\right)$ the gain (or loss) in the profit of a firm with $\operatorname{costs} c_{i}$ when a regulator with bargaining power $\alpha$ reports $\operatorname{costs} c_{j}$ instead of the firm's real costs $c_{i}, i \neq j$. If $\Delta \pi\left(\alpha, c_{i} ; c_{j}\right)>0$, the firm with $\operatorname{costs} c_{i}$ has an incentive to collude.

Defining

$$
\widetilde{\alpha} \equiv 1-\frac{\Delta c q\left(c_{h}\right)}{\int_{c_{l}}^{c_{h}} q(p) d p} \in(0,1)
$$

enables us to formally derive the firm's stake in collusion. ${ }^{11}$

Proposition 1 If $\alpha \leq \widetilde{\alpha}$, collusion is never profitable for the firm. If $\alpha>\widetilde{\alpha}$, only the firm with costs $c_{l}$ has a stake in collusion, which is given by

$$
\Delta \pi\left(\alpha, c_{l} ; c_{h}\right)=\Delta c q\left(c_{h}\right)-(1-\alpha) \int_{c_{l}}^{c_{h}} q(p) d p>0
$$

The inefficient firm does not collude with the regulator, irrespective of its bargaining power. This corroborates the standard result that the inefficient firm does not benefit from manipulating its costs. More relevantly, Proposition 1 also reveals that in a regulatory bargaining context the efficient firm finds it profitable to collude only if the regulator's bargaining power is relatively high, i.e., $\alpha>\widetilde{\alpha}$. Prima facie, this result might appear counterintuitive, since one could expect the firm to have an incentive to collude with a weak regulator. The rationale behind our result lies in the trade-off that the efficient firm faces when colluding with the regulator. Figure 2 illustrates the nature of this trade-off. On the one hand, the firm has a benefit of collusion $\Delta c q\left(c_{h}\right)$, which stems from the higher price it is allowed to charge if the regulator declares that the firm is inefficient. On the other hand, a higher collusive price reduces from $\int_{c_{l}} q(p) d p$ to $\int_{c_{h}} q(p) d p$ the surplus from trade the parties can appropriate through the fixed charge. We know from Lemma 1 that the surplus share of each party depends on its bargaining power. Therefore, the firm has a stake in collusion only if the benefit of a higher price outweighs the

\footnotetext{
${ }^{10}$ Any other regulatory outcome would reveal that the regulator's report is not truthful, and Congress could punish the regulator for its misbehavior.

${ }^{11}$ Note that $\widetilde{\alpha}>0$ since $\int_{c_{l}}^{c_{h}} q(p) d p-\Delta c q\left(c_{h}\right)=\int_{c_{l}}^{c_{h}}\left[q(p)-q\left(c_{h}\right)\right] d p>0$, where the inequality follows from $\frac{\partial q}{\partial p}<0$.
} 


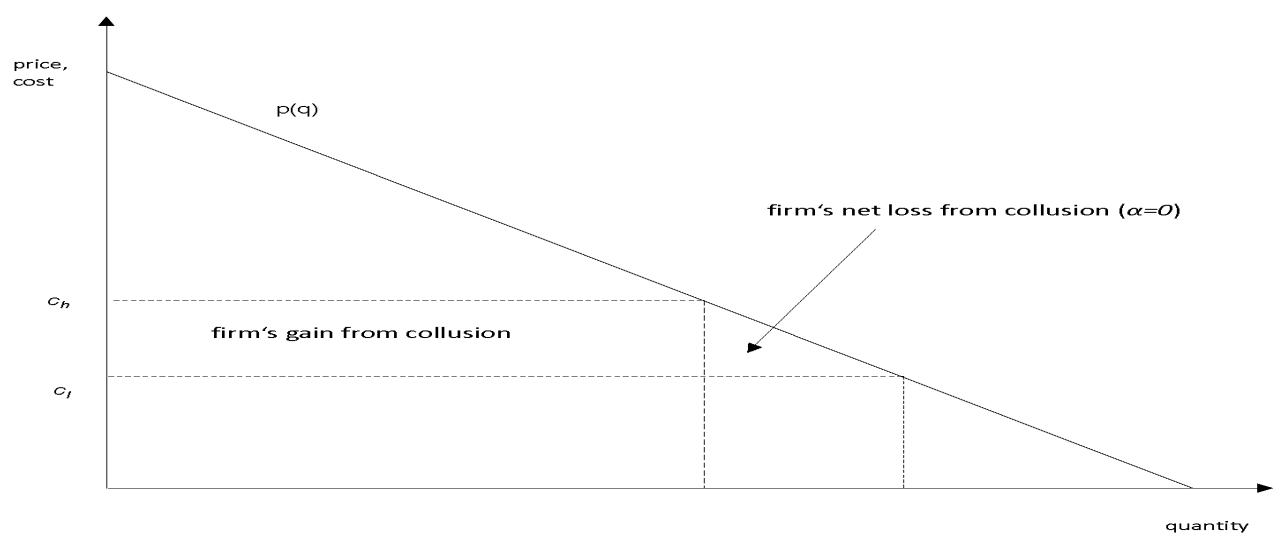

Figure 2: The trade-off from collusion

loss in the surplus from trade the firm incurs in the bargaining process. This is the case when the regulator is relatively strong and can obtain a large portion of the gains from trade.

To illustrate, with a take-it-or-leave-it offer $(\alpha=1)$, the regulator captures all the gains from trade the parties can share. Proposition 1 corroborates the standard result that the firm always has an incentive to collude. At the other extreme, if the firm possesses all the bargaining power $(\alpha=0)$, the firm's benefit of collusion $\Delta c q\left(c_{h}\right)$ is more than offset by the lower gains from trade the firm can obtain, which fall from $\int_{c_{l}} q(p) d p$ to $\int_{c_{h}} q(p) d p$. This result follows from the familiar deadweight welfare loss due to a price distortion above marginal costs.

It is worth investigating the impact of demand elasticity on the possibility of collusion. To this end, we consider an isoelastic demand function of the form $q(p)=p^{-\epsilon}$, where $\epsilon>0$ captures the degree of demand elasticity. Differentiating $\widetilde{\alpha}$ in (5) with respect to $\epsilon$ yields

$$
\frac{\partial \widetilde{\alpha}}{\partial \epsilon}=\frac{c_{h}^{-\epsilon} \Delta c \int_{c_{l}}^{c_{h}} p^{-\epsilon}\left(\ln c_{h}-\ln p\right) d p}{\left(\int_{c_{l}}^{c_{h}} p^{-\epsilon} d p\right)^{2}}>0 .
$$

The less elastic the demand is (i.e., $\epsilon$ decreases), the lower is the threshold $\widetilde{\alpha}$ above which the efficient firm has an incentive to collude. The idea is that lower demand responsiveness to price increases the weight of the firm's benefit of collusion $\Delta c q\left(c_{h}\right)$ relative to the losses $\int_{c_{l}}^{c_{h}} q(p) d p$ in the surplus from trade the parties share in the bargaining process. In particular, when demand is inelastic $(\epsilon \rightarrow 0)$, the deadweight welfare loss from a price distortion disappears, and the firm's 
benefit of collusion exactly compensates the losses in the surplus from trade. Since the firm does not fully internalize these losses (unless it has full bargaining power), its benefit of collusion dominates the cost, and collusion tends to be always profitable $(\widetilde{\alpha} \rightarrow 0)$. This result suggests that in markets for essential services (e.g., energy, sanitation), which typically exhibit some demand rigidity, the threat of collusion between the regulator and the firm is more pronounced. Hence, the design of Congress' optimal response to collusion is even more salient.

\section{The optimal institutional response to collusion}

We investigate three possible institutional responses to collusion: ( $i$ ) Congress tolerates collusion tout court, (ii) Congress deters collusion through an incentive payment to the regulator, (iii) Congress deters collusion through the shutdown of the inefficient firm.

If Congress tolerates collusion, (expected) consumer surplus is

$$
\begin{aligned}
E\left[C S^{c}\right] & =\gamma\left[\nu C S\left(c_{l}\right)+(1-\nu) C S\left(c_{h}\right)\right]+(1-\gamma) C S\left(c_{h}\right) \\
& =C S\left(c_{h}\right)+\nu \gamma \Delta C S,
\end{aligned}
$$

where $\Delta C S \equiv C S\left(c_{l}\right)-C S\left(c_{h}\right)$. When collusion is allowed, Congress expects to receive the consumer surplus associated with an inefficient firm independently of the regulator's type plus the gain from having an efficient firm, which materializes only if the regulator is benevolent.

Congress can deter collusion through an incentive payment to the regulator. In line with the main contributions to the collusion literature (e.g., Baiman et al. 1991; Kofman and Lawarrée 1996), we assume that Congress cannot discriminate between a benevolent and a non-benevolent regulator when offering an incentive scheme. This can reflect institutional and legal constraints which prevent Congress from making a reward contingent on the regulator's type. For instance, the regulatory staff from a certain region can be more inclined to collude, but rewards cannot be differentiated on regional basis (Laffont 2000, Ch. 2). Hence, Congress must remunerate both an honest and a dishonest regulator to prevent collusion, and the incentive payment can be only conditional on the regulator's report about the firm's costs. ${ }^{12}$

To be effective, the incentive payment to the regulator must (at least) cover the firm's stake in collusion (6), discounted by the shadow cost of side transfers $\mu$ the firm incurs when

\footnotetext{
${ }^{12}$ We know from Section 4 that the collusive outcome is such that Congress cannot infer collusion from the regulatory policy. Hence, an incentive payment conditional on the regulatory outcome cannot improve Congress' payoff.
} 
colluding with the regulator. Therefore, in order to preclude collusion, the incentive payment the regulator must receive when declaring that firm is efficient amounts to $s_{r}\left(c_{l}\right)=\frac{\Delta \pi}{1+\mu}$, where $\Delta \pi$ is given by $(6) .{ }^{13}$

Since we know from Proposition 1 that the inefficient firm does not have any incentive to collude, the regulator receives its reservation wage from reporting high costs, i.e., $s_{r}\left(c_{h}\right)=0$. Hence, if collusion is prevented through an incentive payment, (expected) consumer surplus is

$$
E\left[C S^{p}\right]=\nu C S\left(c_{l}\right)+(1-\nu) C S\left(c_{h}\right)-\nu \frac{\Delta \pi}{1+\mu} .
$$

Alternatively, Congress can shut down the production when receiving a report of high costs. This fully removes the incentive to collude at the cost of forgoing the production of the inefficient firm. In case of shutdown, (expected) consumer surplus is

$$
E\left[C S^{s}\right]=\nu C S\left(c_{l}\right)
$$

Comparing (7), (8) and (9) yields the following result.

Lemma 2 Suppose $\alpha>\widetilde{\alpha}$. Then,

(i) tolerating collusion is more desirable than an incentive payment if and only if $\frac{\Delta \pi}{1+\mu} \geq$ $(1-\gamma) \Delta C S$

(ii) the shutdown of the inefficient firm is more desirable than an incentive payment if and only if $\nu \frac{\Delta \pi}{1+\mu} \geq(1-\nu) C S\left(c_{h}\right)$

(iii) the shutdown of the inefficient firm is more desirable than tolerating collusion if and only if $\nu \geq \widetilde{\nu}$, where

$$
\widetilde{\nu} \equiv \frac{\int_{c_{h}} q(p) d p}{\gamma \int_{c_{h}} q(p) d p+(1-\gamma) \int_{c_{l}} q(p) d p} \in(0,1) .
$$

Lemma 2 collects some natural results. Congress prefers to tolerate collusion rather than deter collusion through an incentive payment to the regulator if the cost of incentive payment outweighs the gain in consumer surplus from inducing a self-interested regulator to report truthfully. The option to shut down the inefficient firm is beneficial when the probability of

\footnotetext{
${ }^{13}$ Note that any reward lower than $\frac{\Delta \pi}{1+\mu}$ does not deter collusion, even when the parties bargain over the stake in collusion. In fact, if Congress offered the regulator such a lower reward, the firm could provide a higher payment, which makes collusion profitable for both parties.
} 
an efficient firm is high enough. In particular, Congress prefers to forgo the production of the inefficient firm rather than provide an incentive payment to the regulator if the expected cost of payment outweighs the expected consumer surplus from inefficient production.

We are now in a position to formalize the optimal institutional response to the possibility of collusion.

Proposition 2 Suppose $\alpha>\widetilde{\alpha}$ and $\nu<\widetilde{\nu}$. Then, for $\gamma \geq \widetilde{\gamma} \equiv \frac{\int_{c_{l}}^{c_{h}}\left[q(p)-q\left(c_{h}\right)\right] d p}{\int_{c_{l}}^{c_{h}} q(p) d p} \in(0,1)$, tolerating collusion is optimal if and only if $\mu \leq \widetilde{\mu}$ and $\alpha \geq \alpha^{*}$, where

$$
\begin{gathered}
\widetilde{\mu} \equiv \frac{\gamma}{1-\gamma}-\frac{\int_{c_{l}}^{c_{h}}\left[q(p)-q\left(c_{h}\right)\right] d p}{(1-\gamma) \int_{c_{l}}^{c_{h}} q(p) d p} \geq 0 \text { for } \gamma \geq \widetilde{\gamma} \\
\alpha^{*} \equiv \frac{\int_{c_{l}}^{c_{h}}\left[q(p)-q\left(c_{h}\right)\right] d p}{[1-(1-\gamma)(1+\mu)] \int_{c_{l}}^{c_{h}} q(p) d p} \in(\widetilde{\alpha}, 1] \text { for } \mu \leq \widetilde{\mu} .
\end{gathered}
$$

Otherwise, an incentive payment to the regulator is optimal. The shutdown of the inefficient firm is never optimal.

Proposition 3 Suppose $\alpha>\widetilde{\alpha}$ and $\nu \geq \widetilde{\nu}$. Then, the shutdown of the inefficient firm is optimal if and only if $\nu \geq \max \{\widetilde{\nu}, \widehat{\nu}\}$, where

$$
\widehat{\nu} \equiv \frac{\alpha(1+\mu) \int_{c_{h}} q(p) d p}{\int_{c_{l}}^{c_{h}}\left[q\left(c_{h}\right)-(1-\alpha) q(p)\right] d p+\alpha(1+\mu) \int_{c_{h}} q(p) d p} \in(0,1) .
$$

Otherwise, an incentive payment to the regulator is optimal. Tolerating collusion is never optimal.

Propositions 2 and 3 provide some plausible predictions. Proposition 2 indicates the conditions under which allowing collusion is optimal. This corroborates the result that, when incentive payments cannot discriminate between the regulator's types, collusion may emerge in equilibrium (e.g., Kofman and Lawarée 1996). Specifically, we find that tolerating collusion is desirable when it is too costly to fight through an incentive payment to the regulator. This is clearly the case if collusive agreements are relatively efficient, i.e., $\mu \leq \widetilde{\mu}$, since an incentive reward would be too expensive. Moreover, the probability of facing a dishonest regulator must be low enough, i.e., $\gamma \geq \widetilde{\gamma}$, which limits the welfare loss from collusion. 


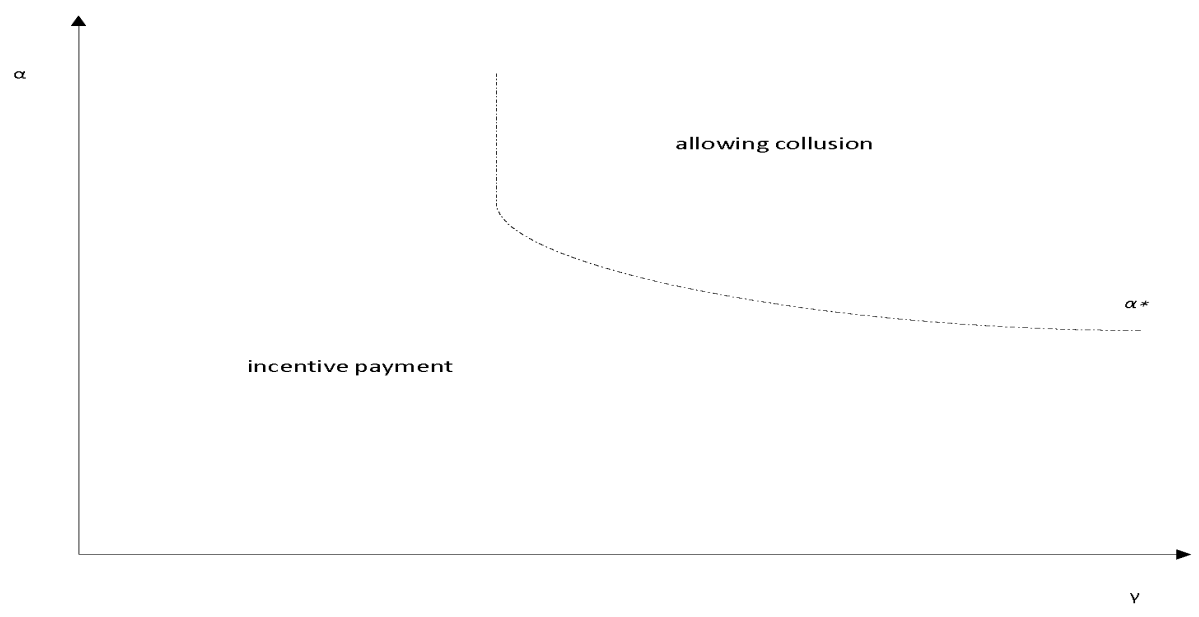

Figure 3: The optimal response to collusion

As Figure 3 illustrates, an additional crucial condition for allowing collusion relates to the parties' bargaining powers in the regulatory process. We know from (6) that a stronger regulator increases the firm's stake in collusion, which makes the incentive payment to preclude collusion more costly. As a consequence, tolerating collusion becomes desirable when the regulator's bargaining power is relatively high, i.e., $\alpha \geq \alpha^{*}$.

Proposition 3 reveals that, if the probability of an efficient firm is sufficiently high, precluding collusion is optimal. This can be achieved either by the shutdown of the inefficient firm or by an incentive payment to the regulator. Differentiating $\widehat{\nu}$ with respect to $\alpha$ yields after some manipulation

$$
\frac{\partial \widehat{\nu}}{\partial \alpha}=\frac{(1+\mu) \int_{c_{h}} q(p) d p \int_{c_{l}}^{c_{h}}\left[q\left(c_{h}\right)-q(p)\right] d p}{\left[\int_{c_{l}}^{c_{h}}\left[q\left(c_{h}\right)-(1-\alpha) q(p)\right] d p+\alpha(1+\mu) \int_{c_{h}} q(p) d p\right]^{2}}<0,
$$

where the inequality follows from $\frac{\partial q}{\partial p}<0$, which implies that the second integral in the numerator is negative. A regulator with a higher bargaining power increases the firm's stake in collusion, and therefore an incentive payment to prevent collusion becomes more costly. This makes the shutdown policy more attractive.

The results in Propositions 2 and 3 suggest that the relative benefits of tolerating collusion and shutdown depend on the probability of an efficient firm. Conversely, irrespective of the 
ex ante distribution of the firm's types, deterring collusion with an incentive payment may be optimal.

As in Section 4, we now investigate the impact of the demand elasticity on the optimal response to collusion, using a demand function of the form $q(p)=p^{-\epsilon}$, where $\epsilon>0$. Differentiating $\widetilde{\gamma}, \widetilde{\mu}$ and $\alpha^{*}$ defined in Proposition 2 yields

$$
\begin{gathered}
\frac{\partial \widetilde{\gamma}}{\partial \epsilon}=\frac{c_{h}^{-\epsilon} \Delta c \int_{c_{l}}^{c_{h}} p^{-\epsilon}\left(\ln c_{h}-\ln p\right) d p}{\left(\int_{c_{l}}^{c_{h}} p^{-\epsilon} d p\right)^{2}}>0 \\
\frac{\partial \widetilde{\mu}}{\partial \epsilon}=-\frac{c_{h}^{-\epsilon} \Delta c \int_{c_{l}}^{c_{h}} p^{-\epsilon}\left(\ln c_{h}-\ln p\right) d p}{(1-\gamma)\left(\int_{c_{l}}^{c_{h}} p^{-\epsilon} d p\right)^{2}}<0 \\
\frac{\partial \alpha^{*}}{\partial \epsilon}=\frac{c_{h}^{-\epsilon} \Delta c \int_{c_{l}}^{c_{h}} p^{-\epsilon}\left(\ln c_{h}-\ln p\right) d p}{[1-(1-\gamma)(1+\mu)]\left(\int_{c_{l}}^{c_{h}} p^{-\epsilon} d p\right)^{2}}>0 .
\end{gathered}
$$

These results indicate that a lower degree of demand elasticity increases the scope for allowing collusion rather than providing the regulator with an incentive payment. We know from the discussion following Proposition 1 that the collusion threshold $\widetilde{\alpha}$ decreases in the demand elasticity. Therefore, in industries with relatively inelastic demand where the threat of collusion is more pronounced, tolerating some form of collusion can be more desirable than an incentive payment, which would be too expensive to implement.

\section{Concluding remarks}

In this paper, we model regulation as the outcome of a bargaining process between a regulator and a regulated firm. In this setting, we investigate the scope for collusion between the two parties, when the regulator monitors the firm's costs and can falsify its report to Congress.

We find that bargaining between the regulator and the firm crucially affects the collusive outcome. The efficient firm has an incentive to collude only if the regulator's bargaining power is high enough. This result follows from the trade-off between the benefit of a higher collusive price and the lower gains from trade the parties can share in the bargaining process. Since these gains are redistributed according to the parties' bargaining powers, a stronger regulator induces the firm to internalize to a lesser extent the losses in the surplus from trade due to cost 
manipulation. Consequently, if the regulator's bargaining power is relatively high, the firm's benefit of collusion due to a higher price outweighs the losses in the gains from trade, and the firm has an incentive to collude. Conversely, a strong firm has a large stake in the gains from trade and therefore it is more reluctant to collude.

Afterwards, we characterize the optimal institutional response to collusion. Our results indicate that allowing collusion can be optimal when the regulator's bargaining power is relatively high. This policy can be also beneficial when consumer demand exhibits some degree of price rigidity. In other circumstances, however, it can be desirable to preclude collusion through an incentive payment to the regulator or the shutdown of the inefficient firm.

Acknowledgements We thank Charles Angelucci, Helmut Bester, Michela Cella, Michele Grillo, Liliane Giardino-Karlinger and Roland Strausz for helpful comments and suggestions. We also thank the participants in seminars at Bari University, Collegio Carlo Alberto of Turin, Politecnico of Milan, as well as at the conferences INFER 2008, SED 2011, CRESSE 2011, EEA 2011. A major part of this paper was written when Raffaele Fiocco worked at Humboldt University of Berlin. The financial support from the Deutsche Forschungsgemeinschaft via SFB 649 'Ökonomisches Risiko' is gratefully acknowledged.

\section{Appendix}

This Appendix collects the proofs.

Proof of Lemma 1. Replacing $t$ with $\pi\left(c_{i}\right)$ from (2) into (3) yields

$$
\max _{p, \pi\left(c_{i}\right)}\left[\int_{p} q\left(p^{o}\right) d p^{o}+p q(p)-c_{i} q(p)-\pi\left(c_{i}\right)\right]^{\alpha} \times\left[\pi\left(c_{i}\right)\right]^{1-\alpha} .
$$

Taking the first-order conditions for $p$ and $\pi\left(c_{i}\right)$ yields $p-c_{i}=0$ and $\pi\left(c_{i}\right)-(1-\alpha) \int_{c_{i}} q(p) d p=$ 0. Standard substitutions imply the results in the lemma.

Proof of Proposition 1. Using (2) and the results in Lemma 1, the change in the profit of a firm with $\operatorname{costs} c_{h}$ when the regulator reports $c_{l}$ is given by

$$
\begin{aligned}
\Delta \pi\left(\alpha, c_{h} ; c_{l}\right) & \equiv \pi\left(\alpha, c_{h} ; c_{l}\right)-\pi\left(\alpha, c_{h} ; c_{h}\right)=\pi\left(\alpha, c_{l} ; c_{l}\right)-\pi\left(\alpha, c_{h} ; c_{h}\right)-\Delta c q\left(c_{l}\right) \\
& =(1-\alpha) \int_{c_{l}}^{c_{h}} q(p) d p-\Delta c q\left(c_{l}\right) \\
& =-\int_{c_{l}}^{c_{h}}\left[q\left(c_{l}\right)-(1-\alpha) q(p)\right] d p<0,
\end{aligned}
$$


where the inequality follows since $\frac{\partial q}{\partial p}<0$ implies that the integrand in the last line is positive.

The change in the profit of a firm with $\operatorname{costs} c_{l}$ when the regulator reports $c_{h}$ is given by

$$
\begin{aligned}
\Delta \pi\left(\alpha, c_{l} ; c_{h}\right) & \equiv \pi\left(\alpha, c_{l} ; c_{h}\right)-\pi\left(\alpha, c_{l} ; c_{l}\right)=\pi\left(\alpha, c_{h} ; c_{h}\right)-\pi\left(\alpha, c_{l} ; c_{l}\right)+\Delta c q\left(c_{h}\right) \\
& =\Delta c q\left(c_{h}\right)-(1-\alpha) \int_{c_{l}}^{c_{h}} q(p) d p
\end{aligned}
$$

which is positive if and only if $\alpha>\widetilde{\alpha}$, where $\widetilde{\alpha}$ is defined in (5).

Proof of Lemma 2. The proof follows from the comparison of (7), (8) and (9).

Proof of Proposition 2. Suppose $\alpha>\widetilde{\alpha}$ and $\nu<\widetilde{\nu}$. From Lemma 2 it follows that $E\left[C S^{c}\right]>$ $E\left[C S^{s}\right]$ for $\nu<\widetilde{\nu}$, which implies that shutdown is dominated by the option of tolerating collusion. Substituting (4) and (6) into (7) and (8) yields after some manipulation

$$
E\left[C S^{c}\right]-E\left[C S^{p}\right]=\alpha[1-(1-\gamma)(1+\mu)] \int_{c_{l}}^{c_{h}} q(p) d p-\int_{c_{l}}^{c_{h}}\left[q(p) d p-q\left(c_{h}\right)\right] d p
$$

which is non-negative if $\mu<\frac{\gamma}{1-\gamma}$ and $\alpha \geq \alpha^{*}$, where $\alpha^{*}>\widetilde{\alpha}$ is defined in the proposition. We have $\alpha^{*} \leq 1$ if $\mu \leq \widetilde{\mu}$, where $\widetilde{\mu}<\frac{\gamma}{1-\gamma}$ is defined in the proposition. Therefore, tolerating collusion is optimal if $\mu \leq \widetilde{\mu}$ and $\alpha \geq \alpha^{*}$. Otherwise, deterring collusion through an incentive payment is optimal.

Proof of Proposition 3. Suppose $\alpha>\widetilde{\alpha}$ and $\nu \geq \widetilde{\nu}$. From Lemma 2 it follows that $E\left[C S^{s}\right] \geq E\left[C S^{c}\right]$ for $\nu \geq \widetilde{\nu}$, which implies that tolerating collusion is dominated by shutdown. Substituting (4) and (6) into (8) and (9) yields

$$
\begin{aligned}
E\left[C S^{s}\right]-E\left[C S^{p}\right] & =\frac{\nu}{1+\mu} \int_{c_{l}}^{c_{h}}\left[q\left(c_{h}\right)-(1-\alpha) q(p)\right] d p-(1-\nu) \alpha \int_{c_{h}} q(p) d p \\
& =\frac{\nu}{1+\mu}\left[\int_{c_{l}}^{c_{h}}\left[q\left(c_{h}\right)-(1-\alpha) q(p)\right] d p+(1+\mu) \alpha \int_{c_{h}} q(p) d p\right] \\
& -\alpha \int_{c_{h}} q(p) d p .
\end{aligned}
$$

Necessary condition for this expression to be non-negative is that the term in (big) square brackets is positive. This is the case for $\alpha>\alpha^{o} \equiv \frac{\int_{c_{l}}^{c_{h}}\left[q(p)-q\left(c_{h}\right)\right] d p}{\int_{c_{l}}^{c_{h}} q(p) d p+(1+\mu) \int_{c_{h}} q(p) d p}$. Since $\widetilde{\alpha}>\alpha^{o}$, the term in square brackets is always positive under the assumptions in the proposition. Standard manipulation implies that the entire expression is non-negative if and only if $\nu \geq \widehat{\nu}$, where $\widehat{\nu}$ is defined in the proposition. Therefore, shutdown is optimal if $\nu \geq \max \{\widetilde{\nu}, \widehat{\nu}\}$. Otherwise, 
deterring collusion through an incentive payment is optimal.

\section{References}

Aidt, T. S. (2003). Economic analysis of corruption: A survey. Economic Journal, 113(491), $632-652$.

Amacher, G. S., Malik, A. S. (1996). Bargaining in environmental regulation and the ideal regulator. Journal of Environmental Economics and Management, 30(2), 233-253.

Armstrong, M., Sappington, D. E. M. (2007). Recent Developments in the Theory of Regulation. In: Armstrong, M., Porter, R. (eds.), Handbook of Industrial Organization, vol. 3. Elsevier Science Publishers, Amsterdam, pp. 1557-1700.

Baiman, S., Evans III, J. H., Nagarajan, N. J. (1991). Collusion and auditing. Journal of Accounting Research, 29(1), 1-18.

Baliga, S. (1999). Monitoring and collusion with 'soft' information. Journal of Law, Economics, and Organization, 15(2), 434-440.

Baron, D. P. (1989). Design of regulatory mechanisms and institutions. In: Schmalensee, R., Willig, R. D. (eds.), Handbook of Industrial Organization, vol. 2. Elsevier Science Publishers, Amsterdam, 1347-1447.

Binmore, K., Dasgupta, P. (1987). The economics of bargaining. Basic Blackwell, Oxford.

Estache, A., Wren-Lewis, L. (2009). Towards a theory of regulation for developing countries: Following Jean Jacques Laffont's lead. Journal of Economic Literature, 47(3), 729-770.

Faure-Grimaud, A., Laffont, J.-J., Martimort, D. (2003). Collusion, delegation and supervision with soft information. Review of Economic Studies, 70(2), 253-279.

Ida, T., Anbashi, M. (2008). Analysis of vertical separation of regulators under adverse selection. Journal of Economics, 93(1), 1-29.

Kahn, A. E. (1988). The economics of regulation: Principles and institutions. MIT Press, Cambridge, MA.

Khalil, F., Lawarrée, J. (2006). Incentives for corruptible auditors in the absence of commitment. Journal of Industrial Economics, 54(2), 269-291. 
Kofman, F., Lawarrée, J. (1993). Collusion in hierarchical agency. Econometrica, 61(3), 629-656.

Kofman, F., Lawarrée, J. (1996). On the optimality of allowing collusion. Journal of Public Economics, 61(3), 383-407.

Laffont, J.-J. (2000). Incentives and political economy. Oxford University Press, Oxford.

Laffont, J.-J., Rochet, J. C. (1997). Collusion in organization. Scandinavian Journal of Economics, 99(4), 485-495.

Laffont, J.-J., Tirole, J. (1990). The politics of government decision-making: Regulatory institutions. Journal of Law, Economics, and Organization, 6(1), 1-31.

Laffont, J.-J., Tirole, J. (1991). The politics of government decision-making: A theory of regulatory capture. Quarterly Journal of Economics, 106(4), 1089-1127.

Laffont, J.-J., Tirole, J. (1993). A theory of incentives in procurement and regulation. MIT Press, Cambridge, MA.

Morriss, A. P., Yandle, B., Dorchak, A. (2005). Choosing how to regulate. Harvard Environmental Law Review, 29, 179-250.

Nash, J. F. (1950). The bargaining problem. Econometrica, 18(2), 155-162.

Nash, J. F. (1953). The two-person cooperative games. Econometrica, 21(1), 128-140.

Osborne, M. J., Rubinstein, A. (1990). Bargaining and markets. Academic Press, San Diego.

Rossi, J. (2011). Regulatory bargaining and public law. Cambridge University Press, Cambridge, UK.

Sákovics, J. (1993). Delay in bargaining games with complete information. Journal of Economic Theory, 59(1), 78-95.

Scarpa, C. (1994). Regulation as a bargaining process: Negotiation over price and cost-reducing investments. Oxford Economic Papers, 46(3), 357-365.

Spulber, D. F. (1988). Bargaining and regulation with asymmetric information about demand and supply. Journal of Economic Theory, 44(2), 251-268.

Spulber, D. F. (1989). Regulation and markets. MIT Press, Cambridge, MA. 
Stigler, G. J. (1971). The economic theory of regulation. Bell Journal of Economics and Management Science, 2(1), 3-21.

Tirole, J. (1986). Hierarchies and bureaucracies: On the role of collusion in organizations. Journal of Law, Economics, and Organization, 2(2), 181-214.

Tirole, J. (1992). Collusion and the theory of organization. In: Laffont, J.-J. (ed.), Advances in Economic Theory. Sixth World Congress, vol. 2. Cambridge University Press, Cambridge, UK, pp. 151-206.

Viscusi, W. K., Harrington, J. E., Vernon, J. M. (2005). Economics of regulation and antitrust. MIT Press, Cambridge, MA. 